\title{
NOTAS HISTÓRICAS SOBRE A FAMÍLIA CACTACEAE NO RIO GRANDE DO SUL (BRASIL) E URUGUAI. I - PERÍODO CLÁSSICO (1818-1950): VIAJANTES NATURALISTAS E BOTÂNICOS EUROPEUS ${ }^{1}$
}

\author{
RODRIGO CORRÊA PONTES ${ }^{2}$ \\ JOSE NEWTON CARDOSO MARCHIORI ${ }^{3}$ LEOPOLDO WITECK NETO $^{4}$
}

\section{RESUMO}

O histórico das descobertas de cactáceas no Rio Grande do Sul e Uruguai é examinado a partir de registros literários dos viajantes naturalistas, horticultores e botânicos que se dedicaram à prospecção e ao estudo destas plantas no espaço regional.

Palavras-chave: Botânica, Cactaceae, História, Rio Grande do Sul, Uruguai.

\section{ABSTRACT}

[Historical notes about the Cactaceae family in the State of Rio Grande do Sul (Brazil) and Uruguay. I - Classic period (1818-1950): naturalist travelers and european botanists].

Relevant findings about the history of Cactaceae family in Rio Grande do Sul State (Brazil) and Uruguay are examined according to literary records of ancient traveling naturalists, horticulturists and botanists who dedicated themselves to the exploration and study of these plants in the regional space.

Keywords: Botany, Cactaceae, History, Rio Grande do Sul, Uruguay.

\section{INTRODUÇÃO}

Distintas paisagens do Rio Grande do Sul e Uruguai, tais como afloramentos rochosos, areais, campos com gramíneas, escarpas e, até mesmo, o interior de florestas densas apresentam ambientes propícios ao estabelecimento de cactáceas, as quais, pela ocorrência fragmentada, deram origem a numerosos endemismos. Outro aspecto a destacar, de início, é que pela beleza das formas geométricas e flores vistosas, essas plantas são muito apreciadas para fins ornamentais, justificando seu cultivo em todo o mundo.

1 Recebido em 05-09-2016 e aceito para publicação em 15-11-2016.

2 Geógrafo, doutorando em Geografia, Programa de Pós-Graduação em Geografia, Universidade Federal de Santa Maria.rodrigocorreapontes@gmail.com

3 Engenheiro Florestal, Dr. Bolsista de Produtividade em Pesquisa (CNPq - Brasil). Professor Titular do Departamento de Ciências Florestais, Universidade Federal de Santa Maria. marchiori@pq.cnpq.br

4 Engenheiro Florestal, M.e., Professor do Colégio Politécnico, Universidade Federal de Santa Maria. lwiteck@gmail.com
Na Europa, o interesse pelos cactos data de princípios do século XIX, quando viajantes naturalistas deram início à busca e estudo dos mesmos, sobretudo no tocante à taxonomia e fenologia, mas sem maior empenho no registro histórico dos achados e respectivos descobridores.

O presente artigo, que busca reunir fatos históricos relativos ao descobrimento de cactos no Rio Grande do Sul e Uruguai, destina-se não apenas aos especialistas neste grupo de plantas e aos amantes da Botânica e de disciplinas afins, mas, inclusive, a profissionais de outras áreas das ciências naturais, bem como a historiadores e pessoas interessadas nesta família botânica.

A elaboração do artigo justifica-se pela ausência de uma bibliografia em língua portuguesa sobre o tema no Rio Grande do Sul. A adição do Uruguai deve-se tanto à inclusão de parte da então província Cisplatina (atual Uruguai) ao território gaúcho no início do século XIX, como pelo fato de diversos exploradores e pesquisadores terem desenvolvido seus trabalhos de campo em ambos os lados da fronteira. 
A lacuna bibliográfica explica-se pelo fato da literatura ser, em grande parte, de difícil acesso e, quando disponível, oferecer dificuldades ou problemas de difícil solução. Felizmente, grande parte dessa história ainda perdura, embora nem sempre em letra de forma. Salientase, ainda, a existência de abundantes equívo$\cos$, sobretudo na grafia de toponímias, bem como de etiquetas com nomes errôneos e/ou trocados, caso de espécimes coletados em uma localidade mas indicados para local distinto.

Outra dificuldade no desenvolvimento do tema prende-se ao fato de que a literatura se encontra, principalmente, em língua alemã, exigindo tradução criteriosa. Não raro, ainda, são os textos em espanhol, francês, holandês, inglês e tcheco. Por fim, ressalta-se que o colecionismo, difusão e estudo de cactáceas sempre foi (e continua a ser) mais intenso em países como Alemanha e Áustria, do que em nosso meio.

Ao longo do texto, os leitores perceberão que a riqueza de dados se avoluma com o passar dos anos. Do início do século XIX até meados do século XX, as informações disponíveis são escassas e fragmentárias, carecendo, por vezes, de dados precisos sobre locais e datas de coleta. Elementos importantes, como esses, mesmo tendo existido um dia, não raramente acabaram extraviados, destruídos ou separados de coleções por motivos variados, inclusive em decorrência de conflitos mundiais.

A partir da década de 1950, as informações mostram maior detalhamento, demonstrando que os viajantes dessa época, mais ligados à ciência botânica, bem como ao cultivo e comércio de plantas em maior escala, reconheciam a importância da precisão nos registros. Tais elementos, de fundamental importância, foram principalmente anotados em diários de viagem e em cartas, constando, em menor parte, em artigos de periódicos ligados a sociedades vinculadas ao colecionismo, bem como ao cultivo e estudo científico dos cactos.

Outro ponto a salientar é que o cultivo (horticultura) sempre foi o principal estímulo na busca de espécies novas desta família botânica.

Até os anos 1980, aproximadamente, ainda era possível a saída de cactos da América do Sul sem maiores problemas, devido à inexistência de fiscalização. A literatura demonstra que a exportação de plantas era prática absolutamente legal e que, até então, nem se pensava no risco do desaparecimento de espécies. Muitos viajantes, aliás, nem iam, pessoalmente, em busca de cactos nessa época, repassando a tarefa para moradores da região, contratados para o trabalho de coleta de plantas e sementes. Desse modo, tanto botânicos como colecionadores contribuíram para as descobertas (ou redescobertas) de espécies novas, as quais, posteriormente, foram introduzidas, cultivadas e propagadas por viveiristas amadores e profissionais, em âmbito internacional.

Para manter o caráter histórico e cronológico do texto preferiu-se conservar os binômios das descrições originais. A nomenclatura atual e sinonímia podem ser consultadas em tabela a ser apresentada em anexo, no artigo final desta série.

Por fim, na realização da presente pesquisa foram recolhidas informações esparsas, constantes em cartas, diários, jornais, livros e revistas, às quais se somam entrevistas com pessoas que vivenciaram ou testemunharam essa verdadeira saga, que é a história do descobrimento das espécies dos cactos no Rio Grande do Sul e Uruguai.

\section{O PERÍODO CLÁSSICO}

No início do século XIX já se encontravam espécies tipicamente pampianas em coleções privadas ou em jardins botânicos da Europa, oriundas da Argentina, Uruguai e Brasil, levadas por viajantes anônimos, sem interesse botânico, ou a pedido de colecionadores.

O primeiro cacto globular pampiano referido na literatura foi Cactus erinaceus, descrito pelo botânico e entolomogista inglês Adrian Hardy Haworth (19-04-1767 - 23-08-1833) em 1819, a partir de exemplar cultivado em 
Norwich, leste da Inglaterra, e publicado em "Supplementum Plantarum Succulentarum" (Haworth, 1819). Ao que consta, Haworth examinou a planta na coleção particular de um amigo - o Sr. Hitchin -, no ano de 1818. De acordo com registro em "Transactions of the Horticultural Society of London", nessa época havia apenas duas coleções notáveis de cactos na Inglaterra: a do próprio Haworth e a de Hitchin (Beaton, 1842). Embora de origem desconhecida, o material costuma ser atribuído ao Uruguai, uma vez que é nesse país que a referida espécie tem maior área de ocorrência. No Rio Grande do Sul, de acordo com recentes trabalhos de campo, o táxon tem distribuição restrita a municípios da metade sul, tais como Herval, Pedras Altas e Arroio Grande, e limite setentrional no município de Bagé.

Um grande destaque no histórico das cactáceas uruguaias e sul-rio-grandenses deve ser creditado a Friedrich Sellow (12-03-1789 ?-10-1831), botânico que entre os anos de 1923 e 1926 realizou extensas viagens pelas então províncias Cisplatina e de São Pedro do Rio Grande do Sul, sendo um dos pioneiros no descobrimento e envio de cactos globulares da região para a Europa (Schumann 1890; Herter 1945). Os exemplares coletados por Sellow foram cultivados por muitos anos no Jardim Botânico de Berlim e, mais tarde, serviram para as descrições taxonômicas realizadas por Johann Heinrich Friedrich Link (02-02-1767 - 01-011851), Christoph Friedrich Otto (04-12-1783 07-12-1856) e Johann Georg Christian Lehmann (25-02-1792 - 12-02-1860), entre outros (Link \& Otto 1827, 1828, 1829; Lehmann, 1827).

De acordo com a "Flora Brasiliensis", Sellow foi responsável pela coleta e envio para o Jardim Botânico de Berlim de Cactus ottonis, $C$. tenuispinus, Echinopsis oxygona, E. multiplex, Echinocactus. denudatus, E. acuatus (?), E. intricatus (?), E. orthacanthus, E. poliacanthus, E. sellowii, E. tephracanthus e E. tortuosus (Link \& Otto 1827, 1828,1829; Lehmann 1826, 1827; Schumann 1890).
Conforme Ritter (1979), Echinocactus denudatus foi descoberto por Sellow entre Caçapava do Sul e Bagé, em janeiro de 1824. No ano seguinte, o botânico prussiano enviou exemplares para o Jardim Botânico de Berlim.

Com relação a Cactus scopa (Sprengel, 1825), C. langsdorffii e C. linkii (Lehmann, 1826, 1827), Echinocactus courantii, E. mammulosus e E. pumilus (Lemaire, 1838), Echinocactus gracillimus, E. hyptiacanthus, E. submammulosus (Lemaire, 1839) e Echinocactus concinnus (Monville, 1839), não se descarta, igualmente, a possibilidade de que a descrição dessas espécies pampianas seja resultado de remessas de Friedrich Sellow ao Jardim Botânico de Berlim, uma vez que a área de ocorrência das mesmas coincide com o trajeto percorrido pelo naturalista no Uruguai e Rio Grande do Sul.

A respeito do espólio do viajante prussiano, que inclui anotações, cartas, desenhos, documentos diversos, exsicatas, animais (insetos, mamíferos, etc.) e amostras de rochas, não custa salientar que este riquíssimo acervo acabou repartido entre os diversos museus de Berlim, após sua morte por afogamento nas águas do rio Doce, em outubro de 1831 (Marchiori et al., 2016). Apesar da destruição de parte do material de herbário da capital alemã ao final da Segunda Guerra Mundial, são numerosas as exsicatas de Sellow que se encontram nas coleções de outras importantes instituições científicas do mundo, citando-se o "Royal Botanic Gardens" (Kew, Inglaterra), o "New York Botanical Garden", o "Muséum National d'Histoire Naturelle" (Paris), o "Natural History Museum" (Londres), o Museu Nacional do Rio de Janeiro, o "Jardin Botanic de l'État" (Bruxelas), o Herbário da Universidade de Cambridge (Inglaterra), os herbários Boissier e Delessert (de Genebra, Suíça), o "Gray Herbarium" (Harvard, USA), o "Botanisches Institut und Botanischer Garten" (Kiel, Alemanha), o "Rijksherbarium" (Leiden, Holanda), o "Lunds Universitet Botaniska Museet” (Lund, Suécia), 
o "Botanitscheski Institut Akademij Nauy" (São Petersburgo, Rússia), o Instituto Botânico da Universidade de Lisboa, o "Botanisches Institut der Universität" (Leipzig, Alemanha), o "Botaniska Museet" (Uppsala, Suécia), o "Naturhistoriska Riksmuseet" (Estocolmo), o "Botanische Tuinen Universiteit Utrecht" (Holanda), o "United States National Herbarium" (Washington), o "Naturhistorisches Museum" e "Botanischer Garten Universität" (em Viena) e o Museu Nacional de Historia Natural de Santiago, Chile (Barreto, 1976).

Alguns diários e relatórios de Sellow foram preservados, mas os registros de suas coletas de Cactáceas foram completamente perdidos (Hackethal, 1995). Desse modo, na ausência de documentos - e com informações disponíveis imprecisas -, não se tem certeza sobre a localidade exata de grande parte de suas coletas. É possível, no futuro, que esta lacuna venha a ser esclarecida (ou pelo menos mitigada) mediante criterioso estudo comparativo entre as informações disponíveis em exsicatas e os registros relativos a outras coleções, tais como a de rochas, juntamente com viagens pontuais, com vistas à reconstituição do roteiro do viajante, o qual foi esboçado, inicialmente, por Urban (1893).

Não custa lembrar que o botânico prussiano não viveu o suficiente para escrever e publicar sobre o extraordinário acervo científico por ele reunido, motivo pelo qual seu nome foi rapidamente esquecido, pelo menos no que concerne aos cactos.

Outra espécie de antigo e difundido cultivo na Europa é Echinocactus eyriesii, descrita pelo botânico e ilustrador francês Pierre Jean François Turpin (11-03-1775 - 01-05-1840) no periódico "Annales de l'Institut de Fromont Horticole" e em "Observations sur La Famille des Cactées", ambos datados de 1830. O táxon presta homenagem ao Sr. Alexandre Eyries, da cidade de Le Havre, França (Turpin, 1830).

De acordo com Charles (2013, p. 28), Eyries informa que foi um capitão francês quem levou de Buenos Aires para a França dois exemplares de Cactus eyriesii em 1827, procedentes, pro- vavelmente, do leste da Argentina ou do sul do Brasil. Na obra de Pfeiffer (1837, p. 72), a origem das plantas consta como sendo de "Buenos Aires". Em expedições recentes, a espécie foi encontrada no oeste do Rio Grande do Sul, entre os municípios de Quaraí e Uruguaiana, preferencialmente em solos arenosos, mas também em afloramentos de rocha.

Ainda em 1830, Link descreveu Echinocactus oxygonus em "Verhandlungen des Vereins zur Beförderung des Gartenbaues in den Königlich Preussischen Staaten 6" (Link \& Otto, 1830), publicação que se pode traduzir como "Registros de transações da Sociedade de Horticultura da Prússia". Conforme indicação do texto, que fornece ilustração, o tipo também seria procedente de coleta realizada por Friedrich Sellow no sul do Brasil.

Em 1837, Ludwig Karl Georg Pfeiffer (0407-1805 - 02-10-1877) descreveu Cereus multiplex em "Enumeratio Diagnostica Cactearum Hucusque Cognitarum", com base em material igualmente atribuído a Sellow. Nessa mesma obra foram descritos Cereus alacriportanus, coletado em Porto Alegre, Echinocactus corynodes, procedente de Maldonado, no sudeste do Uruguai, $e E$. muricatus, do sul do Brasil. A respeito da última espécie, cabe salientar que o autor não menciona coletor nem fornece informações mais precisas sobre o local de coleta (Pfeiffer, 1837); apesar desta lacuna, o mais provável é que também se deva a Friedrich Sellow e, provavelmente, por ocasião de sua viagem de Alegrete a São Borja e Missões, uma vez que a espécie tem distribuição restrita ao centro-oeste do Rio Grande do Sul, principalmente nos atuais municípios de Jaguari, Nova Esperança do Sul, São Vicente do Sul e Santiago.

Ainda no mesmo ano, o botânico alemão Joseph Gerhard Zuccarini (10-08-1797 - 18-021848) criou o gênero Echinopsis, propondo Echinocactus eyriesii como espécie-tipo (Zuccarini, 1837).

Um ano mais tarde, tanto Cereus oxygonus como C. multiplex foram transferidos para o 
gênero Echinopsis, na obra "Abbildung und Bescheibung Blühender Cacteen", enriquecida com belas ilustrações (Pfeiffer \& Otto, 1838).

Em 1838, o botânico e professor francês Charles Antoine Lemaire (01-11-1800 - 22-061871) descreveu Echinocactus courantii, E. mammulosus e E. pumilus na obra "Cactearum aliquot novarum ac insuetarum in horto Monvilliano cultarum accurata descriptio" (Lemaire, 1838). No ano seguinte, o mesmo autor descreveu Echinocactus gracillimus, E. hyptiacanthus e E. submammulosus, em "Cactearum genera nova specieque novae et omnium in horto Monvilliano cultarumex Affinitatibus Naturalibus Ordinatio Nova Indexque Methodicus "; na descrição dessas espécies, que não inclui dados sobre flores e frutos, o autor também não faz referências sobre a procedência das mesmas (Lemaire, 1839).

De acordo com Schumman (1903, p. 130), o período de 1840 a 1880 foi marcado pela ausência de novos registros de cactos procedentes do Rio Grande do Sul e Uruguai. Salienta-se, todavia, a criação do gênero Malacocarpus em 1850, com vistas a abranger algumas espécies até então classificadas em Echinocactus (SalmDyck, 1850).

Em 1886, o botânico inglês Joseph Dalton Hooker (30-06-1817 - 10-12-1911) descreveu Echinocactus joadii, com base em plantas cultivadas no "Royal Botanic Gardens", obtidas por "Mr. Joad", residente em Wimbledon (Inglaterra). $O$ texto indica que as plantas foram coletadas no Uruguai (Hooker, 1886).

Data de 1886, ainda, a publicação de "Handbuch der Kakteenkunde", obra dos botânicos e horticultores alemães Carl Friedrich Föster (1817-1901) e Karl Theodor Rümpler (1817-1891), que inclui as descrições de Malacocarpus martinii (de origem desconhecida), Echinocactus concinnus var. tabularis (oriundo do Uruguai) e E. haselbergii (Förster \& Rümpler, 1886).

A respeito de Echinocactus haselbergii, sabese que a descrição foi elaborada a partir de plantas cultivadas no viveiro de Friedrich Ferdinand
Adolph Haage Jr. (08-04-1859 - 07-05-1930), em Erfurt (Alemanha), não constando qualquer menção ao coletor e origem das mesmas. $\mathrm{O}$ nome específico presta homenagem ao Dr. Haselberg, experiente cultivador de cactos de Stralsund (Alemanha). Sobre a origem, Schumann (1903) informa que os indivíduos foram levados para a Alemanha em 1884, procedentes do Rio Grande do Sul.

Em 1895, a espécie Pilocereus lenninghausii foi mencionada pela primeira vez por Karl Schumann, que atribuiu o binômio a Friedrich Haage, o famoso viveirista de cactos de Erfurt (Schumann, 1895). Essa referência, entretanto, não constitui descrição válida, pois menciona apenas o nome científico, sem fornecer características mais precisas da planta. Um ano mais tarde, Pilocereus lenninghausii apareceu em oferta no catálogo comercial do viveiro da Firma Haage, de Friedrich Ferdinand Adolph Haage Jr., juntamente com uma ilustração e breve descrição (Eggli \& Hofacker, 2010). Segundo Haage (1981), o epíteto específico presta homenagem a "Fred. Guilhermo (Wihelm) Lenninghaus", imigrante alemão que se instalou em Porto Alegre, onde passou a colecionar cactos. A espécie, encontrada em local impreciso no Rio Grande do Sul, teria sido enviada ao viveiro Haage em 1894. Sobre esse ponto, Schumann (1903, p. 130) opina que o mais provável é que a mesma foi inicialmente introduzida na Alemanha em 1884, por August Christian Gustav Ferdinand Haage (1830-1921) e, numa segunda oportunidade, por seu filho Ferdinand Haage Jr., entre 1895-1896.

Outra expressiva contribuição ao conhecimento dos cactos do Rio Grande do Sul deve-se ao alemão Karl Moritz Schumann (17-06-1851 - 22-03-1904), professor de Botânica, natural de Görlitz (Volkens, 1904), que foi curador do Museu de Berlim-Dahlem entre 1880 e 1894 e presidente da "Deutsche Kakteen-Geselschaft", a renomada "Sociedade Alemã de Cactos". Dentre as numerosas contribuições de Schumann à família botânica destacam-se: "Gesamtbeschreibung der Kakteen" (1898) e "Praktikum für 
morphologische und systematische Botanik" (1904). O pesquisador também publicou sobre plantas brasileiras e participou ativamente na organização da monografia de Cactáceas da "Flora Brasiliensis", para a qual forneceu algumas ilustrações e elaborou uma chave de identificação para as espécies descritas (Schumann, 1890; Volkens, 1904), incluindo, de forma organizada e objetiva, diversas espécies sul-rio-grandenses.

Em 1903, Schumann descreveu Echinocactus graessneri, igualmente indicada para o estado sulino. As informações complementares foram fornecidas pelo Sr. Graessner Jr., de Perleberg (Alemanha), responsável pela importação das plantas em agosto de 1903 (Schumann, 1903). Um ano mais tarde, o mesmo autor descreveu Echinocactus arechavaletae, oriunda do Uruguai e que presta homenagem ao ilustre botânico hispano-uruguaio José Arechavaleta y Balparda (27-9-1838 - 16-6-1912).

Em 1904 foi também descrito Echinocactus elachisanthus, pelo francês Frédéric Albert Constantin Weber (17-05-1830 - 21-07-1903). Trata-se de espécie dúbia, nativa no nordeste do departamento de Maldonado, Uruguai (Weber, 1904).

Em 1905, o naturalista ítalo-argentino Carlo Luigi (Carlos Luis) Spegazzini (20-04-1858 01-07-1926) incluiu e/ou descreveu Echinocactus arechavaletae, E. acuatus var. depressus, E. acuatus var. tetracantha, E. caespitosus, E. mammulosus var. typica, E. mammulosus var. pampeana, E. mammulosus var. hircina, E. pampeanus, E. pygmaeus e E. pygmaeus var. phaeodisca em "Cactacearum Platensium Tentamen" (Spegazzini, 1905), obra que firmou seu nome na bibliografia de fanerógamas, ampliando sua já conhecida trajetória em outros campos das ciências naturais, notadamente da micologia, zoologia, mineralogia e geologia.

Em 1923, Spegazzini estabeleceu o gênero Parodia para designar cactos globulares da Argentina e Bolívia. Embora menos conhecido na ciência botânica do que o engenheiro agrôno- mo e agrostólogo argentino Lorenzo R. Parodi (23-1-1895 -21-4-1966), o nome genérico presta homenagem, em verdade, a outro naturalista de mesmo sobrenome - Domingo Parodi (Gênova, 1823 - Paris, 1889) -, que se graduou em Farmácia em Buenos Aires e publicou sobre as floras do Paraguai, de Corrientes e Misiones. A respeito do referido gênero, não custa adiantar que sua distribuição geográfica inclui, atualmente, diversas espécies nativas no Rio Grande do Sul e Uruguai (Hunt, 2006).

Um grande marco no estudo dos cactos do Uruguai deve-se a José Cosme Arechavaleta y Balparda (27-09-1838 - 16-06-1912), botânico e naturalista espanhol que imigrou para Montevidéu em 1855 , onde atuou como farmacêutico e professor universitário de Botânica e de História Natural Médica. Em 1890, Arechavaleta tornou-se diretor interino do Museu de História Natural de Montevidéu e passou a trabalhar exaustivamente em sua notável "Flora Uruguaya", vinda a lume em 1905. Nas mais de cem páginas dedicadas aos cactos nativos, somase, à riqueza de dados, numerosas fotografias e uma chave para identificação de gêneros (Arechavaleta, 1905). A contribuição de Arechavaleta serviu, ainda, para aguçar o olhar de botânicos e especialistas posteriores, tais como Herter, Osten, Marches e Schlosser. Com o tempo, comprovou-se que muitas das descobertas de Arechavaleta eram ecotipos, motivo pelo qual acabaram reduzidas à sinonímia (Hunt et al, 2006). De sua autoria, entretanto, restam Echinocactus apricus, E. fricii, E. floricomus, E. pauciareolatus, E. scopa var. albicans, E. sellowii var. acutata, E. sellowii var. macrocantha, E. sellowii var. macrogonus, E. tacuarembense, E. turbinatus e E. uruguayensis (Arechavaleta, 1905).

Curiosamente, Arechavaleta cometeu alguns erros de identificação. É o caso de Echinocactus tabularis, em que o autor apresenta como ilustração uma foto de Notocactus muellermelchersii em plena floração, espécie que ainda não havia sido descrita. Outra informação dúbia prende-se à ocorrência de Echinocactus 
denudatus nos departamentos de Rivera e Tacuarembó, no norte do Uruguai.

Após a popularização dos cactos globulares coletados por Friedrich Sellow, emergiu na Europa, no início do século XX, outra personalidade que reavivou uma verdadeira "febre" entre os colecionadores de cactos pampianos: Alberto Vojtěch Frič (18-09-1882 - 04-121944). Natural de Praga, esse botânico, escritor e etnólogo tcheco tornou-se conhecido como "caçador de cactos" e chegou a rincões longínquos, além do Oceano Atlântico (Král, 2002). Ao todo, o viajante realizou oito expedições à América do Sul, em países como Argentina, Bolívia, Brasil, Paraguai, Peru e Uruguai, sempre em busca de registros etnológicos e de plantas, especialmente de cactos. A seu respeito, salienta-se que era pela comercialização de plantas, sobretudo, que o pesquisador angariava os recursos necessários a novas viagens.

A região do Pampa começou a ser investigada por Fric em sua segunda expedição, de agosto de 1903 a setembro de 1905, período em que esteve no Uruguai. Na quinta (maio de 1919 a junho de 1920), ele andou pela Argentina e Uruguai; na sétima (de janeiro a junho de 1927), percorreu a Argentina, Brasil, Paraguai e Uruguai e, em sua oitava (e última) viagem (outubro de 1928 a março de 1929), passou pelo Uruguai e Argentina (Neduchal, 2002). Todas estas oportunidades renderam muitas descobertas ao botânico tcheco, principalmente de cactos globulares, que logo se tornaram "moda" no continente europeu.

Impossibilitado de viajar à América do Sul durante a Primeira Guerra Mundial (1914-1918), Friè dedicou-se neste período ao cultivo de cactos, para o que instalou estufas e um jardim experimental em sua casa, na cidade de Praga. O pesquisador gostava de relatar experiências com semeadura, cultivo, cuidados e enxertia de cactos, salientando-se, no tocante a novas espécies, as descrições de Malacocarpus beltranii, $M$. bezrucii, M. bezrucii var. centrispinus, $M$. bezrucii var. cornifer e M. kovaricii (Theunissen, 1985).
Em 1928, Frič publicou o catálogo "Cacti the coming Fashion", em que se menciona, pela primeira vez, a palavra Notocactus, gênero por ele atribuído a espécies globulares sul-americanas de flores amarelas e frutos secos. A espécie utilizada como referência na designação foi Echinocactus schumannianus, nativa do Paraguai (Theunissen, 1985).

Depois dessas viagens à América do Sul, o trabalho de Frič passou a distinguir-se por idéias novas e revolucionárias. Em revisão sobre a classificação da família, o autor elaborou uma "árvore genealógica", antecipando o objetivo perseguido pela atual filogenia. O pesquisador tcheco também apresentou novas metodologias para o estudo da semente e o difícil preparo de plantas na confecção de exsicatas.

Apesar de redigir seus próprios achados, Fric rejeitou a elaboração de diagnoses em latim, norma exigida desde 1935, e acreditava que uma imagem (fotografia), por ser mais fiel, substitui com vantagem qualquer descrição, motivo pelo qual restam válidas apenas suas descrições anteriores ao referido ano.

Muitas décadas mais tarde, os botânicos tchecos Zdenik Fleischer (1905-1978) e Bohumil Schütz (1903-1993) reabilitaram, em 1975, alguns dos antigos achados de Frič, descrevendo Notocactus euvelenovskyi, $N$. mueller-moelleri e Wigginsia rubricostata (Fleischer \& Schütz, 1975). O mesmo aconteceu com Notocactus minimus, descrito a partir de plantas enviadas a Frič pelo Sr. Kolischer, em 1931 (Buining, 1940).

Muitos dos gêneros e espécies criados por Frič são atualmente reconhecidos apenas como sinônimos. No inverno de 1939-1940 ele perdeu grande parte de sua coleção por congelamento. Após esse dano - e sabedor da fome que então grassava no mundo -, Frič passou a realizar experimentos com híbridos e variedades de plantas cultivadas (Theunissen, 1985) em suas estufas e laboratório, realizando, inclusive, cruzamentos intergenéricos de cactos e outras plantas. Mesmo sem perceber sua contribuição, Frič foi uma das personalidades que mais influenciou o universo dos colecionadores de cactos. 
Dos autores que se dedicaram ao estudo e classificação de espécies coletadas por outros e que permanecem quase desconhecidos na literatura -, salienta-se o botânico alemão Alwin Berger (28-08-1871 - 20-04-1931), autor de "Kakteen", obra publicada em 1929 e que alcançou renome em sua época, na qual algumas espécies foram agrupadas no gênero Notocactus, de acordo com a proposição original de Frič (Berger, 1929).

Nas décadas de 1930 e 1940, outros dois eminentes botânicos alemães destacaram-se no estudo dos cactos nativos no Uruguai - Herter e Osten -, dando sequência ao trabalho realizado por José Arechavaleta.

O berlinense Wilhelm (Guillermo) Gustav Franz Herter (10-01-1884 - 17-04-1958) viveu no vizinho país entre 1923 e 1939, associado ao Jardim Botânico e Museu de História Natural. Entre outras atividades, ele também lecionou na "Universidad de La Republica" e foi diretor da "Revista Sudamericana de Botânica" (Schlosser, 1980).

Além de coletar plantas, Herter publicou diversos trabalhos de revisão taxonômica de cactáceas. Em 1930, reconhecendo a existência de dois homônimos no gênero Echinocactus ( $E$. arechavaletai Spegazzini e E. arechavaletae K. Schumann), propôs o binômio Echinocactus. maldonadensis, sanando a questão. Ignorado por muitos autores, este seu táxon foi reconhecido como válido por Hofacker (2010).

Em dezembro de 1933, Herter coletou uma espécie desconhecida em rochas de arenito do "Cerro Galgo", no departamento uruguaio de Rivera. A planta floresceu em cultivo nos anos de 1934 e 1935, apresentando flores rosa-escuras, tonalidade até então incomum em cactos globosos (Werdermann, 1936), motivo pelo qual tornou-se um dos mais populares no gênero Echinocactus: trata-se de E. herteri, descrita pelo também berlinense Erich Werdermann (0203-1892 - 20-04-1959), especialista em cactos colunares.

Em 1942, Herter retribuiu a homenagem com a descrição de Notocactus werdermannianus, coletada pelo "Dr. Walther" no "Cerro Portón”, departamento de Tacuarembó (Osten, 1941). Em 1943, o autor publicou novas combinações, transferindo espécies do gênero Echinocactus para Notocactus (Herter, 1943).

O segundo botânico alemão que atuou intensamente no Uruguai foi Cornelius Osten (1102-1863 - 06-09-1936). Natural de Bremen, ele emigrou em 1896 para Montevidéu, dedicandose à exportação de lã e, por natural inclinação, também à botânica, colaborando com Arechavaleta no Museu de História Natural. Ainda em vida, Osten adquiriu amplo prestígio entre botânicos norte-americanos e europeus da época e, apesar de se considerar um outsider ${ }^{5}$ na scientia amabilis, publicou várias monografias sobre a flora uruguaia (Theunissen, 1993).

Pouco antes de falecer, Cornelius Osten repassou suas anotações e herbário para o Museu de História Natural de Montevidéu. Mais tarde, o eminente mirtólogo Diego Legrand, diretorassistente do referido museu, publicou as notas originais e as excelentes fotografias do botânico teuto-uruguaio em "Notas sobre Cactáceas", obra póstuma, vinda a lume em 1941. Neste meticuloso trabalho, são apresentadas chaves de identificação, descrições detalhadas e fotografias em preto-e-branco de Echinocactus megapotamicus, E. scopa forma ramosus e E. schroederianum, entre outras espécies. A espécie Echinocactus erubescens, de Piriápolis (Uruguai), que segundo o autor seria um híbrido entre E. mammulosus e E. tabularis (Osten, 1941), constitui, todavia, espécie dúbia.

No estudo de Osten percebe-se a oscilação entre o sistema de classificação de Karl Schumann e o dos botânicos norte-americanos Nathaniel Lord Britton (15-01-1859 - 25-06-

\footnotetext{
Expressão usada pelo próprio Cornelius Osten para definir sua relação com a botânica, em carta de 11-02-1931 ao Dr. Benjamin Lincoln Robinson (1864-1935): “yo no pertenezco a la tribu Botánica, solo soy um outsider, comerciante (yo he enviado muchos fardos de lana a USA y Europa), retirado desde hace dos años, la scientia amabilis es mi hobby ..." (Paz \& Bassagoda, 2011).
} 
1934) e Joseph Nelson Rose (11-01-1862 - 0405-1928), que também incluíram os cactos pampianos em sua alentada "The Cactaceae", obra editada entre 1919 e 1923.

Outra importante contribuição aos cactos do Uruguai deve-se a Friedrich Karl Müller Melchers (07-02-1890 - ?-?-1967). Natural de Bremen (Alemanha), ele emigrou para o Uruguai em 1914 e trabalhou em uma indústria até 1942, dedicando-se, após a aposentadoria, ao estudo de vegetais marinhos no Museu Nacional de História Natural de Montevidéu, onde também atuou como bibliotecário voluntário. A respeito de sua pessoa, sabe-se que nas expedições ao interior do país ele dedicava especial atenção aos cactos e que foi o coletor de Notocactus mueller-melchersii e N. rutilans, entre outras espécies (Backeberg, 1935; Daeniker et Krainz, 1948).

Em 1942, o jardineiro suíço Hans Krainz (1305-1906 - 20-05-1980) publicou Notocactus mueller-melchesii var. gracilispinus, coletado na "Sierra de las Ánimas", departamento de Maldonado (Uruguai) e, três anos mais tarde, descreveu Notocactus scopa var. daenikerianus, a partir de sementes oferecidas no catálogo de sementes de 1938, da firma de importação e exportação de Harry Blossfeld (27-02-1913 07-07-1986), botânico e especialista em cactos e orquídeas, natural de Postdam, Alemanha (Krainz, 1945). Blossfeld também contribuiu com a coleta de sementes, sendo que de uma viagem à região de Santa Rosa e Santo Cristo provieram os exemplares que, cultivados na antiga Tchecoslováquia, levaram à descrição de Notocactus ottonis var. venclusianus, de flores vermelhas (Prestlé 1995). Na referida publicação de 1942, foi ainda descrito Notocactus scopa var. glauserianus. Resta acrescentar que a origem de ambas as variedades de Notocactus scopa foi atribuída ao Uruguai, mas sem localidade definida (Krainz, 1945).

Em 1948, Krainz descreveu Notocactus rutilans, em parceria com Albert Ulrich Däniker (12-06-1894 - 29-04-1957), com base em material encontrado e distribuído por Müeller
Melchers em 1936, no departamento de Cerro Largo (Uruguai), próximo à fronteira com o Brasil (Daeniker et Krainz, 1948). No mesmo ano, o botânico alemão Kurt Kreuzinger (19051989) descreveu Notocactus ottonis var. schuldtii a partir de remessa recebida em 1932, procedente do Rio Grande do Sul (Gerloff, 1986).

Curt Backeberg (02-08-1894 - 14-01-1966), outro importante horticultor e taxonomista alemão, também realizou viagens em busca de cactos nas Américas Central e do Sul. Autor de "Die Cactaceae", obra em seis volumes, publicados entre 1958 e 1962, e de "Kakteenlexicon" (1966), Backeberg descreveu novos gêneros, espécies e variedades, caso de Frailea castanea, com ocorrência designada, inicialmente, para o Uruguai (Backeberg, 1935), e estabeleceu os gêneros Acanthocephala e Eriocephala para espécies do Rio Grande do Sul (Backberg, 1938), transferindo-as, mais tarde, para Brasilicactus e Eriocactus, respectivamente (Backeberg, 1942). O autor enfocou aspectos fitogeográficos das distintas espécies e elaborou mapas de ocorrência para subfamílias e gêneros. Resta comentar que muitos de seus gêneros foram posteriormente abandonados ou reduzidos à sinonímia.

Mesmo sem ter visitado o Rio Grande do Sul, Backeberg descreveu duas espécies nativas no estado, juntamente com Otto Voll (1884-1959), outro especialista alemão, responsável pela criação e manutenção da coleção de cactos do Jardim Botânico do Rio de Janeiro (Backeberg, 1949).

De acordo com a descrição de Frailea alacriportana, os exemplares dessa espécie foram inicialmente remetidos a Voll por Ricardo Kennicke (?) e depositados sob o no 14.114 na coleção do Jardim Botânico do Rio de Janeiro; em 1941, novos exemplares foram enviados por Carlos Zuckermann, de Porto Alegre (RS), os quais foram registrados sob o $\mathrm{n}^{\circ} 15.830$. Apesar da descrição não mencionar a localidade tipo, o nome específico alude, inequivocamente, à capital do Rio Grande do Sul.

Parodia alacriportana foi descrita com base em planta coletada por Helmut Berger em 1939 
e depositada sob o n ${ }^{\circ} 15.513$ no Jardim Botânico do Rio de Janeiro. Como localidade-tipo menciona-se "Serra perto de Porto Alegre", sem maiores detalhes (Backeberg, 1949). Segundo o coletor, em carta de 18-01-1941 enviada a Otto Voll, a flor era amarela e de grande tamanho. Apesar de Voll tê-la cultivado a partir de sementes, as plantas não floresceram. A espécie, infelizmente, não voltou a ser coletada e o local preciso de coleta segue desconhecido.

\section{AGRADECIMENTOS}

Os autores registram agradecimentos a Andreas Hofacker (Böblinger) e Wolf-Rainer Abraham (Hillerse), bem como ao professor Marcelo Antonio Rodrigues e ao Colégio Politécnico da UFSM, pelo apoio financeiro à realização desta pesquisa.

\section{REFERÊNCIAS BIBLIOGRÁFICAS}

ARECHAVALETA, J. Cactaceae. Anales del Museo Nacional de Montevideo. v. 2, n. 5, p. ser. 2, 5, p.161-291, 1905.

BACKEBERG, C. Neue Kakteen aus Brasilien. Arquivos do Jardim Botânico do Rio de Janeiro, v. 9, p. 149-174, 1949.

BACKEBERG, C. Kaktus-ABC. 1935. 432 p.

BACKEBERG, C. Blatter für Kakteenforschung, v. 6, p. 7, 21, 1938.

BACKEBERG, C. Cactaceae (Berlin) 1941. v. 2, p 36,76, 1942.

BARRETO, A. Bibliografia Sul-Rio-Grandense. Rio de Janeiro: Conselho Federal de Cultura, 1976. v. 2, p. 1257-1265.

BEATON, D. On the cultivation and management of the Cactus tribe. Transactions of the Horticultural Society of London, v. 2, p. 459470, 1842.

BERGER, A. Kakteen. 1929. 346 p.

BUINING, A. F.H. Nieuwe en wenig bekende notocactussen. Succulenta, v. 19 n. 2, p. 86-87, 1940.

CHARLES, G. Granny' Echinopsis. The Cactus Explorer. n.8, p. 27-34, 2013.

DÄNIKER, A.U; KRAINZ, H. Notocactus rutilans. Sukkulentenkunde - Jahrbücher der Schweizerischen Kakteen-Gesellschaft, n. 2, p.19, 1948
EGGLI, U; HOFACKER, A. Validation of the Name Parodia lenninghausii (Cactaceae), with a note on the lectotypification and orthography of the name. Novon, v. 20, n.1, p.30-32, 2010.

FLEISCHER, Z; SCHÜTZ, B. Uruguayské notokaktusy a wigginsie A.V. Fric. Friciana, v. 8, n. 50, 1975. 48 p.

FÖRSTER, C. F.; RÜMPLER, K. T. Handbuch der Kakteenkunde 2. Leipzig: p. 563-564. 1886.

HACKETAL, S. Friedrich Sellow (1789-1831). Skizzen einer unvollendeten Reise durch Südamerika. Fauna und Flora in RheinlandPfalz, n. 17, p. 215-228, 1995.

HAWORTH, A. Supplementum Plantarum Succulentarum, p.74, 1819.

HERTER, W. Auf den Spuren der Naturforscher Sellow und Saint-Hilaire. Botanische Jahrbücher, n. 74, p.119-149, 1945.

HERTER, G. Notocactus maldonadensis (Herter) Herter, Revista Sudamericana de Botanica. n. 7, p. 216, 1943.

HOOKER, J. D. Curtis's Botanical Magazine. Londres v. 112, tab. 6867, 1886.

HUNT, D.R; TAYLOR, N; CHARLES, G. The New Cactus Lexicon. Milborne Port, 2006. 899 p.

KRAINZ, H. Neue und seltene Kakteen aus der Stadtischen Sukkulenten-Sammlung Zürich. Schweizer Garten, n. 7, p. 199- 201, 1945.

KRAINZ, H. Notocactus mueller-melchersii var .gracilispinus. Kakteenkunde, p. 33-35, 1962.

KRÁL, L. 120 let - A. V. Fric. Ostník v. 315, n. 31, p. 171-173, 2002.

LEHMANN, J.G.C. Pugillus Plantarum in botanico Hamburgensium Horto ocourrentium, Hamburg, p. 316-318, 1826.

LEHMANN, J.G.C. Index semina in horto botanico Hamburgensi 1826 collecta , n. 17, 1826.

LEHMANN, J.G.C. Semina in horto botanico Hamburgensi 1827 collecta, n.16, 1827.

LEMAIRE, C. Cactearum aliquot novarum ac insuetarum in horto monvilliano cultarum accurata descriptio, 1838.

LEMAIRE, C. Cactearum genera nova speciesque novae et omnium in horto Monvilliano cultarum. Paris, p. 20-22,1839.

LINK, J. H. F; OTTO, F. Über die Gattungen Melocactus und Echinocactus. Verhandlungen des Vereins zur Beförderung des Gartenbaues in den Königlich Preussischen Staaten. Band 3, p. 412-232, 1827. 
LINK, J. H. F; OTTO, F. Icones Plantarum Rariorum Horti Regii Botanici Berolinensis cum descriptionibus et colendi ratione. Oehmigke, Berlim, 1828.

LINK, J. H. F; OTTO, F. Icones Plantarum Rariorum Horti Regii Botanici Berolinensis cum descriptionibus et colendi ratione. Erster Band 29. 1829.

LINK, J. H. F; OTTO, F. F. Icones Plantarum Rariorum Horti Regii Botanici Berolinensis cum descriptionibus et colendi ratione. n. 29, 1930.

LINK, J. H. F; OTTO, F. Eine neue Cactus Art, Echinocactus oxygonus Link. Verhandlungen des Vereins zur Beförderung des Gartenbaues in den Königlich Preussischen Staaten. v. 6, p. 149-424, 1830.

MARCHIORI, J.N.C.; PONTES, R.C.; MARCHIORI NETO, D.L. Textos inéditos de Friedrich Sellow. 1 - Viagem às Missões Jesuíticas do Rio Grande do Sul. Balduinia, Santa Maria, n. 51, p. 12-24, 2016.

MONVILLE, M. Echinocactus concinnus. L'Horticulteur Universel, p. 222, 1839.

NEDUCHAL, J. Alberto Vojtech Fric und und seine Notokakteen. Notocactus, 2002, 103 p.

OSTEN, C. Notas sobre Cactaceas. Anales del Museo de Historia Natural de Montevideo, 1941. 154 p.

PAZ, E.A.; BASSAGODA, M.J. Historia de la Botánica en el Uruguay. Dos grandes botánicos extranjeros afincados en el Uruguay - Ernest Gibert y Cornelius Osten. Ciência \& Ambiente, Santa Maria, n. 42, p. 121-146, 2011.

PFEIFFER, L. Enumeratio Diagnostica Cactearum Hucusque Cognitarum. Berlim, p. 47-68, 1837.

PFEIFFER, L; OTTO, F. Abbildung und Bescheibung Blühender Cacteen. Berlim, v.1, 1838.

PRESTLE, K. H. Auf der Suche nach Notocactus ottonis (Lehm.) Berger ex Backeb. var. vencluianus Schütz. Internoto. v. 16, n. 2, 1995, p. $43-48$

RITTER, F. Kakteen in Südamerika. Band 1. Brasilien/Uruguay/Paraguay. Friedrich Ritter Selbstverlag, Spangenberg, 1979. 374p.

SALM-DYCK, J. G. Cacteae in Horto Dyckensi Cultae anno 1849. Bonn, p. 141-142, 1850.

SCHLOSSER, H. In memorian Prof. Wilhelm Herter.
Kakteen und andere Sukkulenten, v. 31, n. 9, p. 272-273, 1980.

SCHUMANN, K. Cactaceae. In: Martius C.F.P, von Eichler, A.W. \& Urban I. Flora Brasiliensis, v 4, p. 185-322, 1890.

SCHUMANN, K. Echinocactus (Malacocarpus) arechavaletai. In: Arechavaleta, J.Anales del Museo Nacional de Montevideo, v. 2, n.5, p. 242244, 1905

SCHUMANN, K. Ein neuer Echinocactus aus Südbrasilien. Monatsschrift für Kakteenkunde, n. 9, v. 13, p. 129-130, 1903.

SPEGAZZINI, C L. Breves notas cactológicas. In: Anales de la Sociedad Cientifica Argentina. n. $96,1923.70 \mathrm{p}$.

SPEGAZZINI, C L. Cactacearum Platensium Tentamen. Anales Del Museo Nacional de Buenos Aires. n. 11, p. 477-521, 1905.

SPRENGEL, C. P. J. Cactus scopa. Systema Vegetabilium, Göttingen, v. 2, p. 494, 1825.

THEUNISSEN, S. Zu den Wurzeln zurück (27). Dr. Cornelius Osten Biografische Daten. Internoto. v. 14, n. 4, p. 132-138, 1993.

THEUNISSEN, J. Entdeckungen neuer Kakteenarten von A. V. Fric. Notocactus 5. 1985. 30 p.

TURPIN, P.J.F. Annales de l'Institut Royal Horticole de Fromont. n. 2, p.153-157, 1830.

TURPIN, P.J.F. Observations sur la famille des Cactées. Huzard, 1830. 69 p.

URBAN, I. Biographische Skizzen. 1. Friedrich Sellow (1789-1831). Botanische Jahrbücher fürSystematik, Pflanzengeschichte und Pflanzengeographie. Leipzig, n. 17, p. 177-198, 1893.

VOLKENS, G. Karl Schumann. Berichte der Deutschen Botanischen Gesellschaft, v. 22, p. 49-59, 1904.

WEBER, F. A. C. Bulletin du Muséum d'Histoire Naturelle, n. 10, p. 387-388, 1904.

WERDERMANN, E. Echinocactus herteri Werd. nov. spec., ein Rotblühender Notocactus aus Uruguay. Revista Sudamericana de Botânica, v. 3, n. 4-6, p. 143-145, 1936. 